\title{
Development of Simulated Scenarios for Quadricycle Safety
}

\author{
Giuseppina Pappalardo*, Salvatore Cafiso, Alessandro Severino \\ Department of Civil Engineering \& Architecture, University of Catania, Via Santa Sofia 64, 95123, Catania, Italy
}

Received January 12, 2021; Revised March 31, 2021; Accepted April 18, 2021

\section{Cite This Paper in the following Citation Styles}

(a): [1] Giuseppina Pappalardo, Salvatore Cafiso, Alessandro Severino , "Development of Simulated Scenarios for Quadricycle Safety," Civil Engineering and Architecture, Vol. 9, No. 3, pp. 584-594, 2021. DOI: 10.13189/cea.2021.090302.

(b): Giuseppina Pappalardo, Salvatore Cafiso, Alessandro Severino (2021). Development of Simulated Scenarios for Quadricycle Safety. Civil Engineering and Architecture, 9(3), 584-594. DOI: 10.13189/cea.2021.090302.

Copyright $\mathrm{C} 2021$ by authors, all rights reserved. Authors agree that this article remains permanently open access under the terms of the Creative Commons Attribution License 4.0 International License

\begin{abstract}
In Italy, quadricycles can be driven by the youngest category of drivers of 14 years of age. The increasing popularity together with the low-level of safety regulation of these vehicles compared to cars gives cause for concern. Simulators, considered as a training method, provide a realistic reproduction of driving environments so that they can be used to improve driving skills and risk awareness to novice and young drivers. Simulation trial can also be used to evaluate driving performance about safety. At first, the more appropriate simulated accident scenarios for training of young drivers were identified as those with the highest frequency in real world crashes. Since the ISTAT national crash data base includes a multitude of information, but no unique scenario code, it was necessary to use all the available data to classify the proper scenario associated with each crash. To this aim, the taxonomy theory was applied to create a comparable structure for the database. For training and evaluation tests, five accident scenarios were implemented in a simulation course that lasted approximately fifteen minutes. Ten participants driving a simulated quadricycle in a simple one screen simulator were used as a sample to test the working performance of the scenarios. Finally, Traffic Conflict Technique was applied to measure performance indicators derived from the data acquired during the simulation tests. The results confirmed data from the accident database about the location of accidents in rural intersections.
\end{abstract}

Keywords Quadricycle, Safety, Taxonomy, Scenario, Simulator, Driver

\section{Introduction}

During 2016, in 28 European countries, about six hundred 15-17 years old drivers died in road traffic accidents [1]. Young people are more likely to be killed or seriously injured on the road, in almost every country in Europe, than older people [2]. The risks are even higher for young moped and motorcycle riders. Studies have shown that the likelihood of being injured in a collision is 10-20 times higher amongst moped riders of all ages compared to car drivers [3, 4]. Safe driving requires good knowledge, skills and understanding of risk. These competencies are acquired by means of continuous and varied exposure to traffic, that is by means of driving. Moreover, young drivers drove more frequently during high risk hours and under high risk circumstances and distraction as a cause of driving errors was more prominent in novices than in experts [2].

Specific measures must be taken to counteract and eliminate the negative effects that immaturity and inexperience may cause. Firstly, measures that raise the overall safety level of the traffic system such as adequate enforcement (alcohol, speed and safety belt), safe roads and cars, will increase safety levels of inexperienced and young drivers. Apart from these general measures, effective measures aimed to increase the amount of driving experience before solo driving, and to protect against high risk situations in the first phases of solo driving should be implemented. Notable possibilities for improvements of driving skills and hazard perception before solo driving can be found in the driver instructions. In this study Youngest Drivers are defined as drivers of 


\section{4-20 years old.}

L6 Quadricycles (Figure 1), sometimes mentioned as micro-cars or mini-cars, are currently type-approved under the motorcycle Framework Directive 2002/24/EC [5, 6] and are classified as:

- Unladen mass less than $425 \mathrm{~kg}$;

- Maximum speed not exceeding $45 \mathrm{~km} / \mathrm{h}$;

- Engine cylinder capacity less than $50 \mathrm{~cm}^{3}$ (petrol engines);

- Maximum net power does not exceed $4 \mathrm{~kW}$ (diesel engines);

- Maximum continuous rated power does not exceed 4 $\mathrm{kW}$ (electric vehicles).

Europe's motorized quadricycle sales volume stood at around 45,819 units in 2014 and reached 52,181 units in 2018 [7]. Most of these vehicles are in France with a significant presence also in Italy. Quadricycles, with good fuel economy and lower emissions, are expected to become more popular with the increasing public concern associated with environmental issues. Also, the number of congestion/road merging schemes is likely to increase, and quadricycles, if they continued to be treated favorably, would again be an attractive option for consumers.

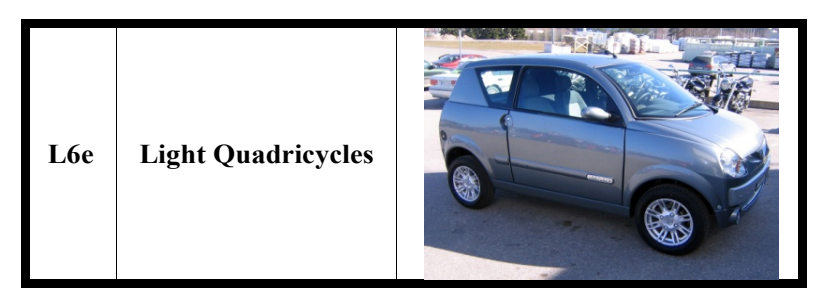

Figure 1. Example of L6e vehicles considered in the study
In most European countries, quadricycles can be driven with only a moped license. For this reason and because it is considered safer than a moped, quadricycles are very popular among teenagers. But accident data showed that this finding isn't correct. Looking at the Italian crash data, in terms of fatalities (K) and fatalities plus injuries (KI) [8] and estimating a travelled distance (DT) of $12,500 \mathrm{~km}$ for cars [9] and 3,500 for motorcycles [9], the average values in the period $2016-2018$ are reported in Table 1. The number of registered vehicles $(\mathrm{V}, \mathrm{crash} / 100,000$ vehicle) is available from [10]. From Table 1, it can be seen that the quadricycle $\mathrm{KI}$ casualty rate $(\mathrm{KI} /(\mathrm{V} \cdot \mathrm{DT})=27.4$ casualties $/ 10^{7}$ vehicle $\mathrm{km}$ ) is significantly higher than for cars (1.9). The fatality rate $\left(\mathrm{K} /(\mathrm{V} \cdot \mathrm{DT})=\right.$ fatalities $/ 10^{7}$ vehicle $\mathrm{km})$ is 11 times that of passenger cars $(0.03)$ and nearly 2 times higher than mopeds (0.12).

Starting from these findings, the purpose of this study was to select crash scenarios relevant to young drivers of quadricycles. Such scenarios could be used as a training method with simulators for giving experience with traffic conflicts and for improving risk awareness of young drivers. Some of these scenarios were implemented to perform a simple simulator experiment with the aim to investigate how data from virtual simulations can be used to evaluate driving performance during severe traffic conflicts.

This paper was divided into three main sections:

1. selection and features of scenarios

2. design and application of such scenarios in a virtual environment;

3. analysis of experimental results.

Table 1. Official figures in Italy on quadricycle safety

\begin{tabular}{|c|c|c|c|c|c|c|}
\hline & $\mathrm{KI}$ & $\mathrm{K}$ & $\mathrm{KI} / \mathrm{V}$ & $\mathrm{K} / \mathrm{V}$ & $\mathrm{KI} /(\mathrm{V} \cdot \mathrm{DT})$ & $\mathrm{K} /(\mathrm{V} \cdot \mathrm{DT})$ \\
\hline Quadricycle & 811.33 & 9.7 & 959.0 & 11.5 & 27.4 & 0.33 \\
\hline Car & 93,154 & 1203 & 242.1 & 3.1 & 1.9 & 0.03 \\
\hline Motorcycle & 50,343 & 745.7 & 752.2 & 11.1 & 21.5 & 0.32 \\
\hline Moped & 12,435 & 116 & 465.1 & 4.3 & 13.3 & 0.12 \\
\hline
\end{tabular}

* For quadricycle and moped DT is assumed equal to motorcycle 


\section{Materials and Methods}

\subsection{Selection of Scenarios}

The design of an efficient set of scenarios to assess the crash likelihood of a young driver required not only knowledge of novice skill deficit, but also knowledge of the scenarios in which skills are most compromised [11, $12,13,14,15]$.

The term "scenario" was used in the safety field to designate a model of an accident process characterized by chains of facts, actions, casual relations and consequences in terms of damage to people and property [16]. A crash scenario can be referred as a category of accidents presenting overall similarities from the point of view of the chain of events and causal relationships in the different phases leading up to the collision.

Based on these findings, a crash scenario can be defined in detail using limited in-depth accident studies $[17,18$, 19]. Since the aim of this study was to evaluate the frequency of relevant scenarios in the overall accident situation, information must be collected from wide national accident databases.

A set of scenarios have been defined based on data available in the Italian data base for serious road crashes (KI) on public roads [8]. The ISTAT database included some information, but not any accident classification which can be associated to a unique scenario. To create a scenario code, it was necessary to select and use all available and suitable information to classify the proper scenario associated with each crash recorded in the ISTAT database. To this aim, the taxonomy theory was used to create a comparable structure for the database used in the analysis. The taxonomy was non-exclusive, and the codes were categorical, denoting the absence or presence of a certain feature [20].

Similar, to other European countries' accident classifications [21, 22], a list of 54 scenarios, divided into five categories (single vehicles, out intersection, at intersection, vehicle-pedestrian, and vehicle-obstacles) was created to classify crashes using the ISTAT database.

A list of Road configuration, Collision typology, Target Vehicle maneuver and Partner of Collision, consistent with the ISTAT codes, was defined and associated with each scenario. It was necessary to check each combination of Road, Collision, Maneuver and Partner settings to ascertain that each combination was uniquely associated with only one scenario, avoiding any possible repetition or ambiguity. The relevant scenarios of crashes involving young drivers on quadricycles were ranked based on their frequency in the database of crashes from 2016 to 2018. For rural and urban areas, the frequency distributions of the top ten scenarios are reported in Figure 2. Scenarios with the highest frequency and representative of different typologies of collision type and vehicle maneuver were selected for the simulation experiment (Figure 3). IDs 43, 10 , and 36 were selected in the rural area for the higher proportion. ID9 and ID46 were selected in the urban area as alternative scenarios with significant proportions in crash frequency.

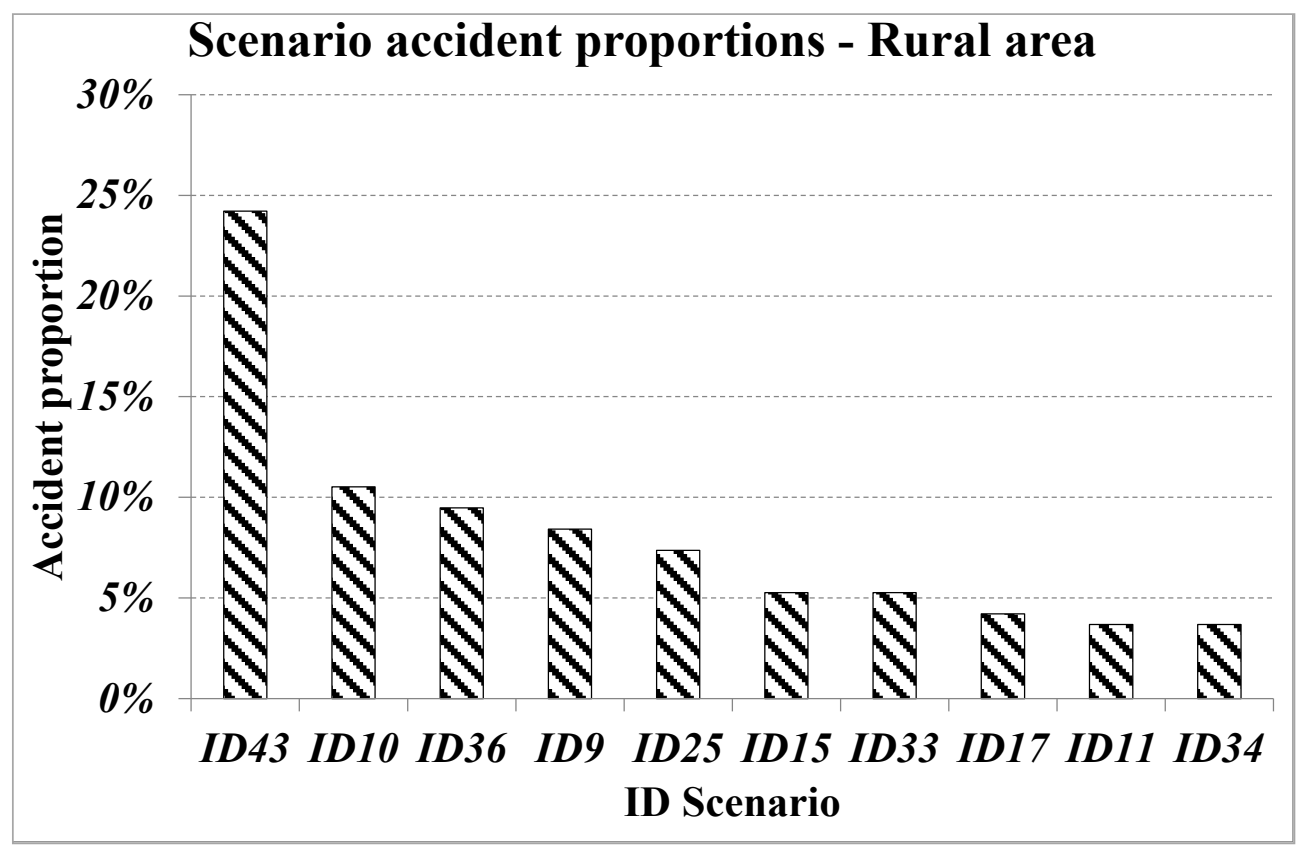




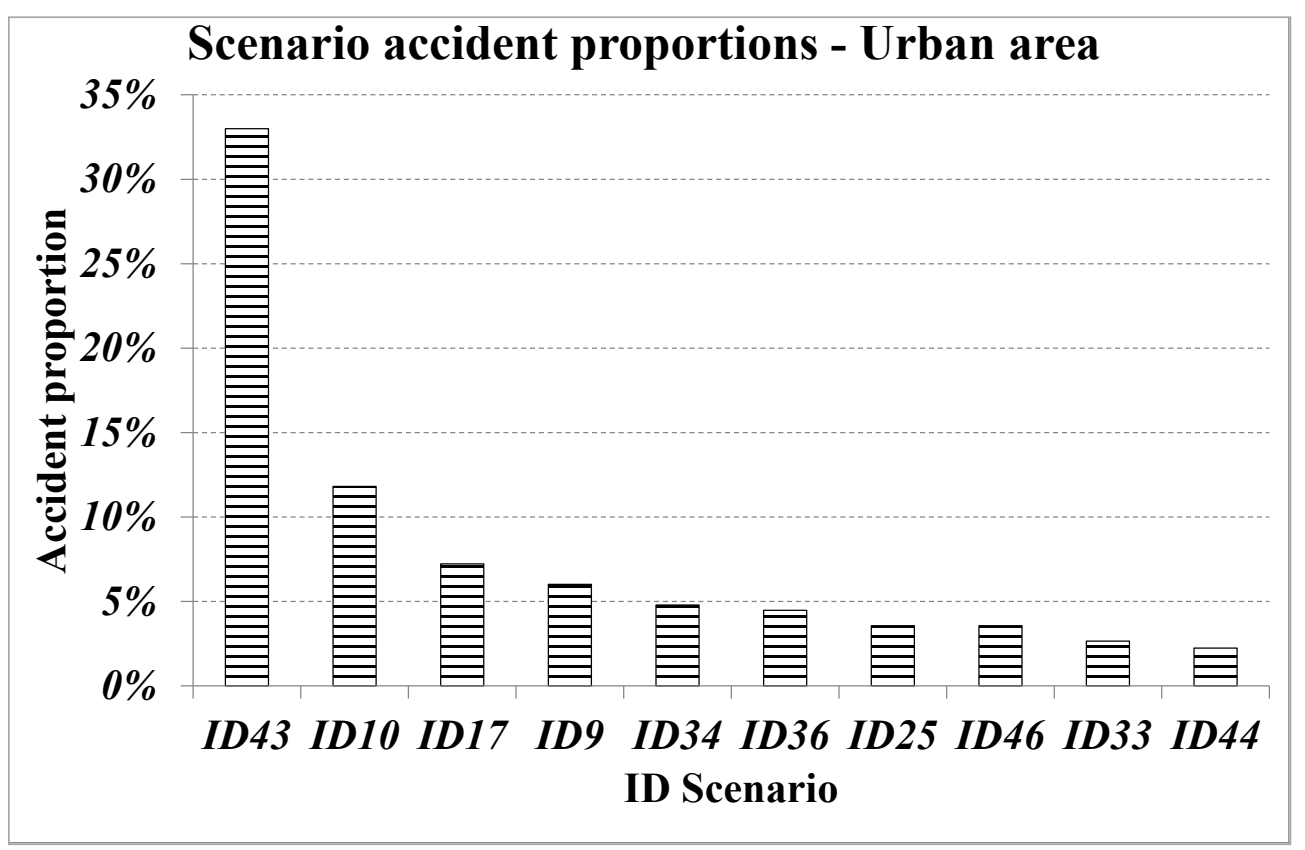

Figure 2. Scenario accident proportions - Rural and urban area

\begin{tabular}{|c|c|c|c|c|c|c|}
\hline Code & Diagram & Area & Road & Collision & Target vehicle maneuver & Partner settings \\
\hline ID10 & $\begin{array}{c}\uparrow \\
\uparrow \\
0 \\
0 \\
0\end{array}$ & Rural & Straight road & Rear end & $\begin{array}{c}\text { Regular driving } \\
\text { Distracted driving } \\
\text { Safety distance not respected } \\
\text { Speeding }\end{array}$ & $\begin{array}{c}\text { Regular driving } \\
\text { Distracted driving } \\
\text { Safety distance not respected } \\
\text { Speeding } \\
\text { Maneuvering for parking }\end{array}$ \\
\hline ID36 & 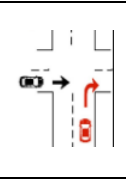 & Rural & Intersection & $\begin{array}{l}\text { Head on } \\
\text { Side swipe }\end{array}$ & $\begin{array}{c}\text { Regular driving } \\
\text { Distracted driving } \\
\text { Signs and/or marks not } \\
\text { respected } \\
\text { Speeding } \\
\end{array}$ & Overtaking \\
\hline ID43 & 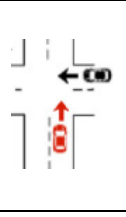 & Rural & Intersection & $\begin{array}{l}\text { Angle } \\
\text { collision }\end{array}$ & $\begin{array}{c}\text { Regular driving } \\
\text { Distracted driving } \\
\text { Safety distance not respected } \\
\text { Signs and/or marks not } \\
\text { respected } \\
\text { Speeding } \\
\end{array}$ & Crossing (no turns) \\
\hline ID9 & 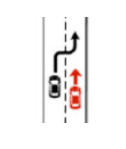 & Urban & Straight road & Rear end & $\begin{array}{l}\text { Maneuvering (parking or } \\
\text { leaving, driveway maneuver) }\end{array}$ & $\begin{array}{c}\text { Regular driving } \\
\text { Distracted driving } \\
\text { Safety distance not respected } \\
\text { Speeding }\end{array}$ \\
\hline ID46 & $*\left|\begin{array}{c:c}i \\
\\
\vdots \\
0 \\
0\end{array}\right|$ & Urban & $\begin{array}{l}\text { Straight road } \\
\text { Curve }\end{array}$ & $\begin{array}{c}\text { Pedestrian } \\
\text { collision }\end{array}$ & $\begin{array}{c}\text { Regular driving } \\
\text { Speeding } \\
\text { Maneuvering } \\
\text { Pedestrian right of way not } \\
\text { respected }\end{array}$ & $\begin{array}{l}\text { Suddenly coming out from behind } \\
\text { parked vehicle or bus stop } \\
\text { Crossing road illegally } \\
\text { Crossing legally at a pedestrian } \\
\text { crossing }\end{array}$ \\
\hline
\end{tabular}

Figure 3. Scenarios selected for simulation [23] 


\subsection{Simulation of Scenarios}

Driving simulators have been utilized to help novice drivers, racing training, road safety scientific research, and as entertainment at home. Driving simulators offer various advantages compared to real vehicles, including [24]:

1. They are easy to control, make, reproduce and normalization. Changing the traffic mode, weather conditions, and the road design can be easily adjusted based on the needs of the researcher or designer. It will also give the developer more room to design different scenarios and enables the user to try and practice freely for any amount of time. By using simulators, drivers can experience driving under the exact same conditions and the same scenarios decided by researchers. This is an important factor for producing research results.

2. Gathering data will be easier and more precise. With a driving simulator, measuring performance will be more accurate and efficient. On the other hand, gathering data with a real vehicle is problematic when collecting corresponding, accurate data. It is difficult to determine the distance between two vehicles in real time because the vehicles can't easily be manipulated by researchers. While in the simulation, data can be recorded more easily and precisely because everything about the simulation can be manipulated at any time.

3. Experiencing and encountering accidents without being physically harmed. It is possible to study dangerous driving situations by putting the driver in dangerous driving situations, which is ethically challenging when using a real vehicle.

4. Ease in feedback and instruction. It is possible to pause, reset, or replay the same, established scenario many times. Feedback and instruction can be delivered in different ways such as speech and visual overlays used to highlight dangerous features in the environment.

However, simulators have several known disadvantages and challenges, including:

1. Limited physical, perceptual, and behavioral fidelity. Low-fidelity simulators may evoke unrealistic driving behavior and therefore produce invalid research outcomes. Simulator fidelity is known to affect user opinion. Participants may become demotivated by a limited-fidelity simulator and prefer a real vehicle instead (or a costlier high-fidelity simulator for that matter).

2. Shortage of research demonstrating validity of simulation. A growing body of evidence indicates that driving-simulator measures are predictive for on-the-road driving performance. However, only a few studies have investigated whether skills learned in a driving simulator transfer to the road.
3. Simulator sickness, especially in older people or over demanding driving conditions. Simulator sickness symptoms may undermine training effectiveness and negatively affect the usability of simulators. This is a serious concern, but fortunately, useful technological and procedural guidelines are available to alleviate it. Research shows that simulator sickness is less of a problem for young drivers. Experience shows that limiting the horizontal field of view, avoiding sharp curves or stops during driving, and using short sessions ( $\leq 10 \quad \mathrm{~min})$ with enough rest breaks significantly reduces simulator sickness.

For this study it was prominent that the driving simulator is the only safe way of exposing drivers to dangerous situations in a training trial. As a case study, both rural and urban scenarios were developed as virtual simulation training tools, implementing five scenarios (Figure 3 ) with the highest frequency of accidents involving young quadricycle drivers.

SCANeR ${ }^{\mathrm{TM}}$ studio software was used for the simulations based on a looping itinerary selected in the "Riviera" terrain model (Figure 4).

The main vehicle of the scenario (target vehicle) was a dynamic model called "Midget", expressly developed by Oktal for this case study. Midget respects fundamental quadricycle characteristics in regards to power and weight (350 kg and $4 \mathrm{~kW}$ ) and dynamic features as breaking and steering. Speed and maneuvers of the autonomous vehicles were synchronized with speed and position of the main vehicle to create a randez vous and traffic conflict situations characterizing the different scenarios. Often, the simulation software followed rules, designed to improve standard simulation, which made the definition of a collision scenario difficult. For example, the autonomous vehicles had rules to avoid erroneous maneuvers (e.g. overtaking at the intersection, wrong direction lane) and collisions with other vehicles. Some of these rules had to be forced or evaded to permit the scenario development.

As an example, scenario (ID43) made the autonomous vehicle enter the intersection at the same time of the driven one, then forcing it to engage the intersection without observing priority rules.

To create a rendez vous, the autonomous vehicle speed was at first a function of the driven vehicle speed, following the relationship:

$$
V_{2}=V_{1} \cdot \frac{d_{2}}{d_{1}}
$$

in which $d_{1}$ and $d_{2}$ respectively were autonomous vehicle and main vehicle distances to the intersection. When the autonomous vehicle reached a specified distance or time to the potential collision point its speed was fixed and remained constant.

In some scenarios where hard breaking may be expected, a visual rain effect was introduced reducing the grip coefficient. 


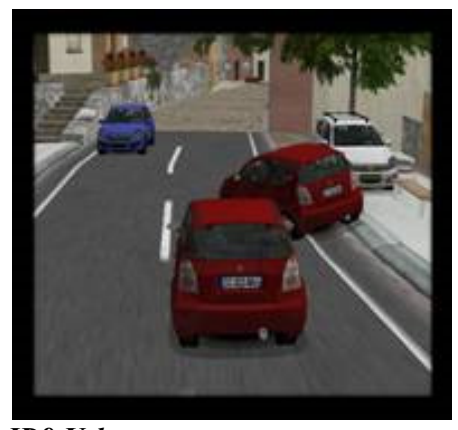

ID9 Urban

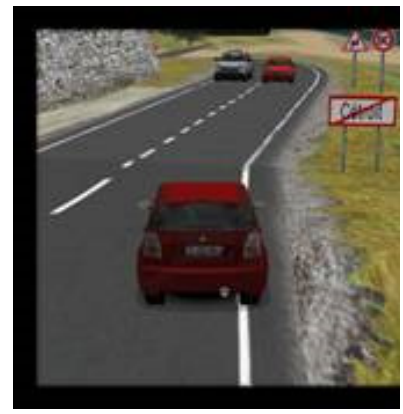

ID36 Rural

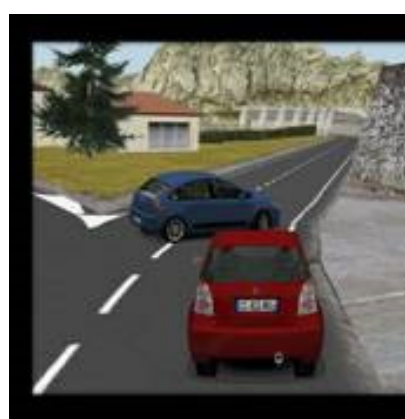

ID43 Rural

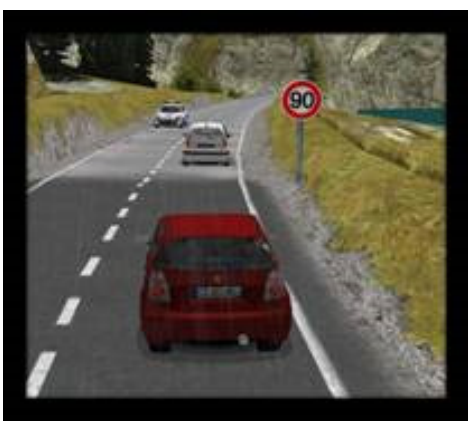

ID10 Rural

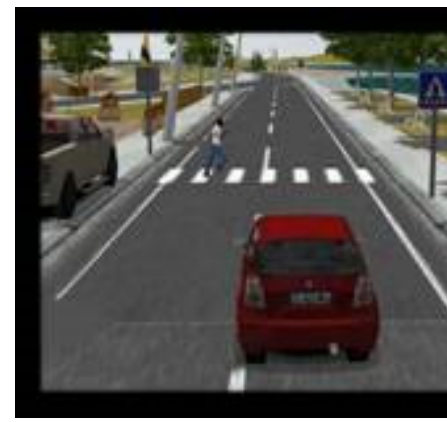

ID 46 Urban

Figure 4. Accident scenarios in virtual environmental

\subsection{Experimental Results and Evaluation}

Ten volunteers participated in the study. The sample consisted of 4 females and 6 males, 1 with passenger car driving experience less than $5,000,5$ with experience ranging from 5,000 to 10,000 and 4 with experience higher than $10,000 \mathrm{~km}$ per year. Each driver was trained to drive the simulator at the beginning of the test with a "loop" scenario which lasted about 5 minutes. This training phase was made using the same terrain file, including the same weather and grip conditions and setting the same itinerary, but without including autonomous vehicles or any kind of traffic conflict. The loop purpose was to adapt the driver to simulator commands and feelings, of virtual light car characteristics and to the track before the real test, allowing them to focus only on driving during the experimental simulation. After completing the training loops, the five accident scenarios were introduced into the trip, no information was given regarding the events to come. The trip lasted approximately 8 minutes, depending on the driver's speed and maneuvers (Figure 5).

Sometimes the scenario simulation ended in a collision between the driven vehicle and the autonomous vehicle, but scenarios were designed to give a chance to the driver to avoid the collision by applying an evasive maneuver (e.g. braking, steering, passing), therefore, generally the simulation concluded without or with few collision events.

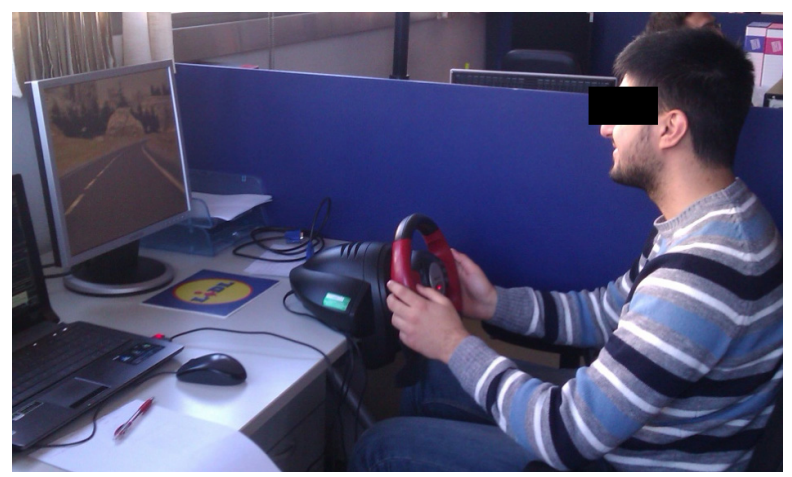

Figure 5. Simulation test drive

Experimental tests were useful to check not only the feasibility of the simulation in reproducing the collision scenarios identified as the most representative of crashes involving young drivers of quadricycles, but also the possibility to acquire data from the simulation to evaluate driver performance during a severe traffic conflict. This information can be used as feedback for instructors and trainees.

Traffic Conflict Technique was used as a reference to measure the severity of the conflict when the collision didn't occur. Depending on the traffic conflict characteristics, different performance measures were carried out from the data recorded during simulation [25, $26,27]$. 


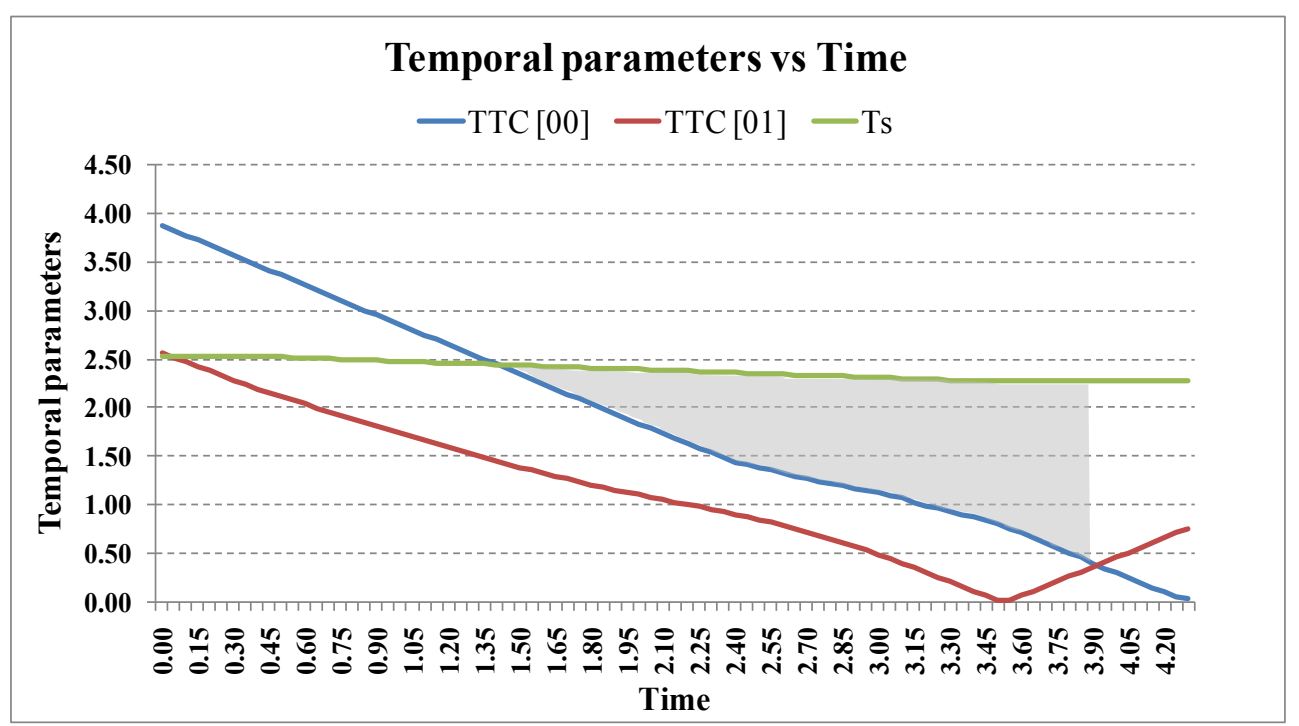

Figure 6. Temporal parameters TTC and Ts vs Time. Measure of conflict risk (ID 43/ ID 36)

\section{Intersection scenarios (ID 36, ID 43, ID46)}

Time To Collision (TTC) and Stopping Time (Ts) for main and autonomous vehicles were evaluated using data recorded by the system at a frequency of $20 \mathrm{~Hz}$ :

$$
\begin{gathered}
\operatorname{TTC}_{v}(i)=\frac{\sqrt{\left(x_{v i}-x_{r}\right)^{2}+\left(y_{v i}-y_{r}\right)^{2}}}{V v i} \\
\operatorname{TTC}_{\mathrm{v}}(\mathrm{i})=\frac{\sqrt{\left(\mathrm{x}_{\mathrm{vi}}-\mathrm{x}_{\mathrm{r}}\right)^{2}+\left(\mathrm{y}_{\mathrm{vi}}-\mathrm{y}_{\mathrm{r}}\right)^{2}}}{\mathrm{Vvi}} \\
T_{s}(i)=T_{r}+\frac{V_{v i}}{g \cdot f}
\end{gathered}
$$

with:

$\mathrm{x}_{\mathrm{vi}}, \mathrm{y}_{\mathrm{vi}}$ : vehicle coordinates at instant $\mathrm{i}$;

$\mathrm{x}_{\mathrm{r}}, \mathrm{y}_{\mathrm{r}}$ : potential conflict point coordinates;

$\mathrm{V}_{\mathrm{vi}}$ : vehicle speed at instant $\mathrm{i}$;

while $\mathrm{T}_{\mathrm{r}}, \mathrm{g}$ and $\mathrm{f}$ are reaction time, gravity acceleration and grip coefficient, respectively. A reaction time value of $1.07 \mathrm{~s}\left(\mathrm{~T}_{\mathrm{r}}\right)$ and different values of $\mathrm{f}$ were set according to weather and road conditions [19].

TTC and Ts for main (00) and autonomous (01) vehicles varied during the conflict phase generated by the scenario. An example of results is plotted in Figure 6. The extension of the area highlighted in Figure 6 was a measure of the conflict risk [19].

\section{Car following scenario (ID 10)}

In this case the potential conflict point was not fixed but it is represented by the autonomous vehicle stopping point. Main vehicle TTC was a measure of the conflict risk:

$$
\operatorname{TTC}(i)=\frac{\operatorname{Gap}_{i}}{V_{m i}}+\frac{V_{a i}^{2}}{2 \cdot a_{a i}}-\frac{V_{m i}}{2 \cdot a_{m i}}
$$

with:

$\mathrm{V}_{\mathrm{mi}}, \mathrm{a}_{\mathrm{mi}}$ : main vehicle speed and deceleration at instant i;

$\mathrm{V}_{\mathrm{ai}}, \mathrm{a}_{\mathrm{ai}}$ : autonomous vehicle speed and deceleration at instant $\mathrm{i}$;

$\mathrm{G}_{\text {api }}$ : distance gap between main and autonomous vehicles at instant $\mathrm{i}$

$$
\operatorname{Gap}_{i}=\sqrt{\left(x_{a i}-x_{m i}\right)^{2}+\left(y_{a i}-y_{m i}\right)^{2}}
$$

$\mathrm{x}_{\mathrm{ai}}, \mathrm{y}_{\mathrm{ai}}$ : autonomous vehicle coordinates at instant $\mathrm{i}$;

$\mathrm{x}_{\mathrm{mi}}, \mathrm{y}_{\mathrm{mi}}$ : main vehicle coordinates at instant $\mathrm{i}$.

TTC varied during the conflict phase generated by the scenario. An example of results is plotted in Figure 7. The minimum value of TTC or the amount of area subtended by the TTC line was a measure of the conflict risk [19]. 


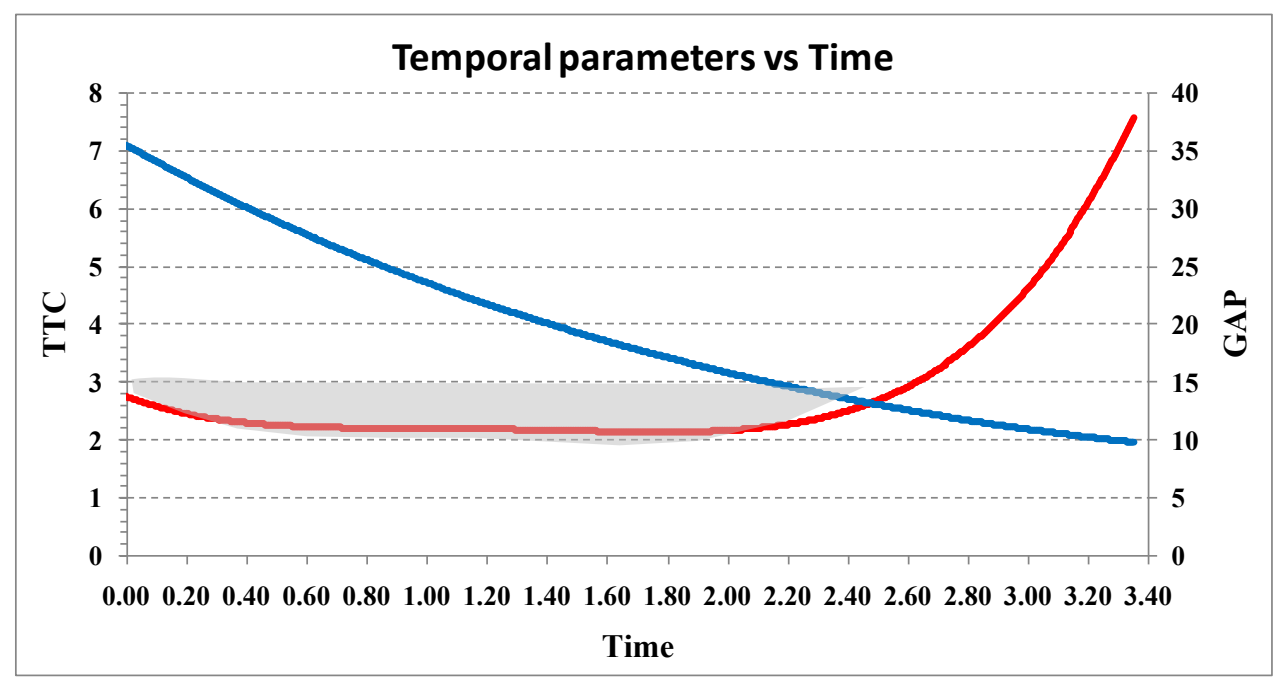

Figure 7. Temporal parameters TTC and Gap vs Time. Measure of conflict risk (ID 10)

\section{$\underline{\text { Scenario ID 9, ID10 (TTC) }}$}

In scenarios ID 9 and again in ID 10, Traffic Conflict measures of main vehicle TTC and Ts were evaluated at the starting instant of the evasive maneuver (e.g. initial pressure on breaking pedal).

$$
\begin{gathered}
T T C=\frac{\sqrt{\left(x_{v}-x_{r}\right)^{2}+\left(y_{v}-y_{r}\right)^{2}}}{V_{v}} \\
T_{s}=T_{r}+\frac{V_{v}}{g \cdot f}
\end{gathered}
$$

with:

$\mathrm{x}_{\mathrm{v}}, \mathrm{y}_{\mathrm{v}}$ : main vehicle coordinates at evasive maneuver starting instant;

$\mathrm{x}_{\mathrm{r}}, \mathrm{y}_{\mathrm{r}}$ : potential conflict point coordinates;

$\mathrm{Vv}$ : main vehicle speed at evasive maneuver starting instant;

$\mathrm{Tr}, \mathrm{g}$ and $\mathrm{f}$ respectively were reaction time, gravity acceleration and adherence coefficient (different values according to weather and road condition, as set in the simulation scenario).

To identify the evasive maneuver starting instant, it was necessary to check case by case the accelerator, brake and steering wheel recorded data of the main vehicle. Usually the chosen instant was the break one. The difference in TTC-Ts was a measure of the time available to the driver to avoid the collision, therefore it was chosen as a measure of conflict risk.

After simulations for each test driver, five performance measures were carried out corresponding to the five scenarios encountered in the trip.

To compare the results, the values of the Traffic Conflict (TCs) parameters were normalized to the value obtained by the scenario designer (T0) (Figure 8).

Results were normalized to make them comparable to the different scenarios and to give a reference of "normal" behavior (i.e. score 1).

This test was considered as a reference result gained by a driver with very good knowledge of scenarios and simulation tools. After normalization for each test driver, the score ranged between $0-2$. The score was assumed equal to zero if a collision occurred, 1 when the Traffic Conflict measure equalizes the T0 one, a cut-off of 2 was assumed to limit the maximum value.

Results of scores for each driver and mean values are reported in Figure 8, showing a way to compare driver performance in simulation tests. An increase in score is related to a safer development of conflict scenarios. 


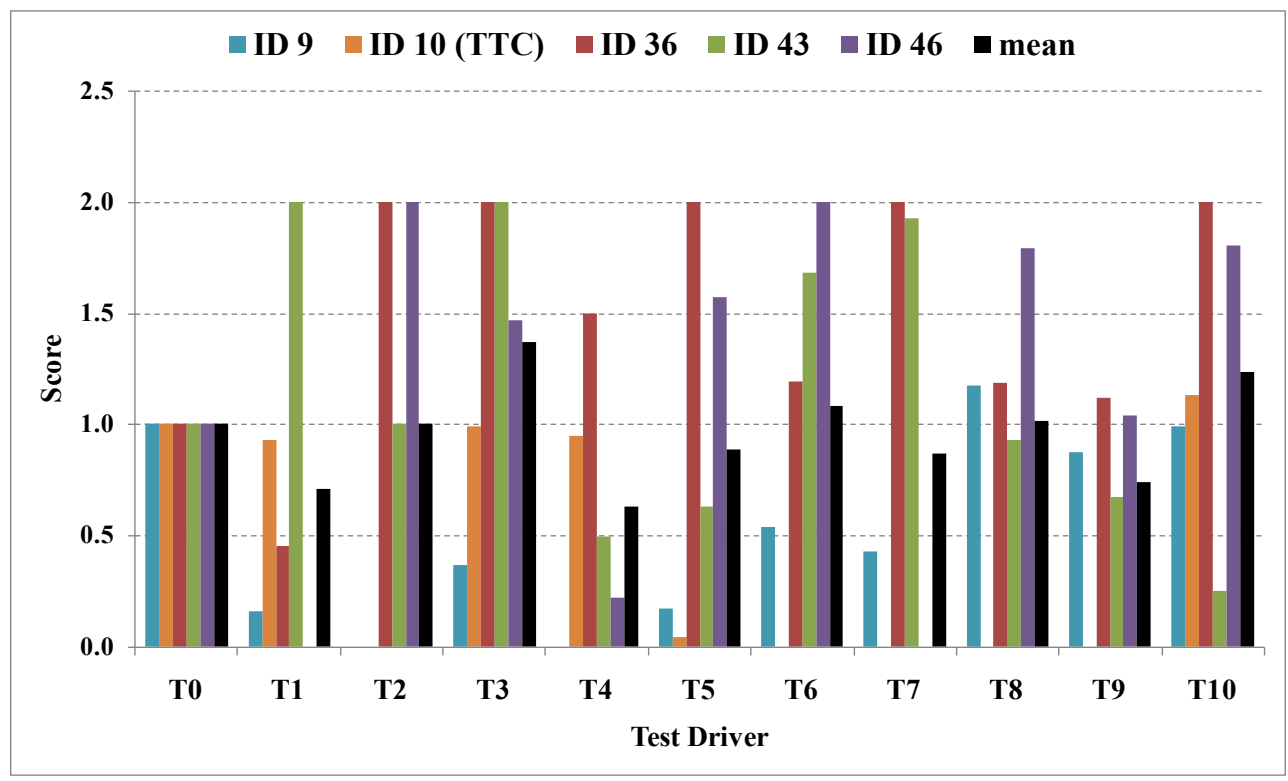

Figure 8. Score values of test drivers

\section{Conclusions}

At 14 years the youngest drivers had access to "quadricycles", four wheel vehicles with a maximum speed limit of $45 \mathrm{~km} / \mathrm{h}$. Figures from Italy showed a crash rate 11 times higher for quadricycles than for traditional passenger cars. Moreover, in Italy, about $50 \%$ of crashes involving quadricycles were with an "under 20 years old" driver.

In this context, possibilities for improvements of driving skill and hazard perception of young drivers can be found in simulation training aimed to increase the amount of driving experience and risk awareness before solo driving.

Starting from these considerations, the purpose of this study was to select crash scenarios relevant to the training of young drivers of quadricycles. A taxonomic study was performed to identify 54 scenarios able to classify any crashes involving quadricycles recorded in the ISTAT database.

This approach presented some limitations in the detailed definition of the spatio-temporal evolution of a scenario if compared to in-depth accident investigations studies which use police reports, maps and photographs of the accident site. On the other hand, only analyzing the broad crash database gave the opportunity to select simulation scenarios relevant to specific classes of drivers, road environments and vehicle types. Scenarios with the highest frequencies in the crash history should be used to perform training with simulators to give experience of traffic conflicts with the highest probability of occurrence in real life. For this reason, in recent years, the number of road-based studies using driving simulators is growing significantly. This allows evaluating controlled situations that otherwise would require disproportionate observations in time and/or cost. A simulator with a good control in the scenarios can teach a wide range of cognitive abilities that are required to deal with complex roads and conditions of difficult traffic, including appropriates situation awareness, hazard perception, decision taking and defensive techniques of driving. The main value simulation can bring about improvement research by helping collect data on phenomena that researchers can hardly observe. In this way, simulation can help describe individual and organizational behavior, generate theory and evaluate improvement interventions.

Some scenarios relevant to young driver of quadricycles were implemented to perform a simple simulator experiment with the aim of investigating how data from virtual simulations can be used to evaluate driving skills and risk awareness. Scenarios were properly designed to give a chance to the driver to avoid the collision by applying an evasive maneuver (e.g. braking, steering, passing), therefore, in general, the simulation was concluded without or with few collision events.

Experimental tests were useful to check not only the feasibility of the simulation in reproducing the traffic conflict scenarios, but also the possibility to acquire data from the simulation to evaluate the driver performance during a severe traffic conflict. The information can be used as feedback for instructors and trainees. Results are not conclusive in the assessment of performance of the test drivers participating in the experiment due to the limitation of the simulation test, but they were representative of data management and evaluation opportunities.

Simulation software designed to improve standard simulation made it difficult to define collision scenarios where autonomous vehicles were forced to collide with others or to violate driving rules. Software specifically 
designed for a training simulation would be preferred.

Depending on the scenario characteristics, different Traffic Conflict measures must be carried out. In the paper two indicators were analyzed: Time to collision and Stopping time. Time to collision (TTC) is the most well-known time-based safety indicator. TTC refers to the time remaining before the rear-end accident if the course and speed of vehicles are maintained. TTC has proven to be an effective measure for discriminating critical from normal behaviors in car-following situations. The major shortcoming of TTC is the assumption of constant vehicle velocities, during collision course. Furthermore, the stopping time is used when in an emergency, a driver must bring their vehicle to a stop in the shortest distance possible. Absolute values of these measures were depending not only on the driver maneuvers but also on scenario design. Therefore, results need to be normalized to a reference value for a comparative study. The possibility of encountering dangerous driving conditions in a safe environment is useful for novice drivers to improve risk awareness, but, during testing, drivers realizing the simulation scope change their driving approach by becoming circumspect of unexpected events and showing a reduction in speed. Therefore, to evaluate the real driving performance and not only the single scenario, the overall simulation must be designed to create a proper alternation of safe and scenario events also with an incentive to maintain speed at suitable levels (e.g. limited time to conclude the test). Driving simulators can introduce a better analysis due to research developed would allow to obtain data at a lower cost, lesser risk and greater control over the variables under study.

\section{REFERENCES}

[1] European Commission, Annual Accident Report. European Commission, Directorate General for Transport, June 2018. Online available from https://ec.europa.eu/transport/road sa fety/sites/roadsafety/files/pdf/statistics/dacota/asr2018.pdf

[2] Atchison, L. Reducing casualties involving young drivers and riders in Europe. YEARS project, European Transport Safety Council (ETSC), December 2016. Online available from

https://etsc.eu/wp-content/uploads/2017_01_26_young_driv ers_report.pdf

[3] Cafiso, S., La Cava, G., Pappalardo, G. A logistic model for Powered Two-Wheelers crash in Italy. PROCEDIA: SOCIAL \& BEHAVIORAL SCIENCES, vol. 53, p. 881-890, 2012. ISSN: 1877-0428, doi: 10.1016/j.sbspro.2012.09.937

[4] Cafiso, S., La Cava, G., Pappalardo, G. A Comparative Analysis of Powered Two Wheelers Crash Severity among Different Urban Areas. PROCEDIA: SOCIAL \& BEHAVIORAL SCIENCES, vol. 53, p. 891-900, 2012. ISSN: 1877-0428, doi: 10.1016/j.sbspro.2012.09.938

[5] DIRECTIVE 2002/24/EC OF THE EUROPEAN
PARLIAMENT AND OF THE COUNCIL of 18 March 2002 relating to the type-approval of two or three-wheel motor vehicles and repealing Council Directive 92/61/EEC. Online available from https://eur-lex.europa.eu/LexUriServ/ LexUriServ.do?uri=CONSLEG:2002L0024:20050517:EN: PDF

[6] REGULATION (EU) No 168/2013 OF THE EUROPEAN PARLIAMENT AND OF THE COUNCIL of 15 January 2013 on the approval and market surveillance of two- or three-wheel vehicles and quadricycles. Online available from https://eur-lex.europa.eu/LexUriServ/LexUriServ.do?uri=OJ :L:2013:060:0052:0128:EN:PDF

[7] Istituto per la Protezione e la Ricerca Ambientale (ISPRA) Dimensione della flotta veicolare Online available from https://annuario.isprambiente.it/ada/downreport/html/6824

[8] ISTAT. Statistica degli incidenti Stradali. Istituto Nazionale di Statistica, Roma, Italy. Online available from http://www.istat.it/it/archivio/44757

[9] Isfort. $15^{\circ}$ Rapporto sulla mobilità degli italiani. Online available from https://www.isfort.it/wp-content/uploads/201 9/09/Rapporto_Mobilita_2018.pdf

[10] ACI. Consistenza parco veicoli al 31/12/2019, Online available from http://www.aci.it/laci/studi-e-ricerche/dati-estatistiche/veicoli-e-mobilita.html

[11] McDonald, C.C., Tanenbaum, J.B., Lee, Y., Fischer, D.L., Mayhew, D.R, Winston, F.K. Using Crash Data to Develop Simulator Scenarios for Assessing Young Novice Driver Performance, Transportation Research Record Journal of the Transportation Research Board, 2012, doi: 2321:73-78, $10.3141 / 2321-10$

[12] Filtness, A., Tones, M., Bates, L., Watson, B., Williamson, A. How would changing driver training in the Queensland licensing system affect road safety? Deliverable 2: Simulators for skill acquisition training and assessment, and their impact on road safety. Centre for Accident Research \& Road Safety - Queensland, November 2013 Online available from

https://www.tmr.qld.gov.au/-/media/Safety/roadsafety/Road -safety-research-reports/report-2-simulators.pdf?la=en

[13] Oron-Gilad, T., Parmet, Y. Can a driving simulator assess the effectiveness of Hazard Perception training in young novice drivers? ATS International Journal, Special Issue 2014 Vol1, pp. $65-76$

[14] Rodwell, D., Hawkins, A., Haworth, N., S. Larue, G., Bates, L., Filtness, A. What do driver educators and young drivers think about driving simulators? A qualitative draw-and-talk study, Transportation Research Part F: Traffic Psychology and Behaviour, Volume 62, 2019, pp. 282-293, ISSN 1369-8478, https://doi.org/10.1016/j.trf.2019.01.008.

[15] Martín-delosReyes, L. M., Jiménez-Mejías, E., Martínez-Ruiz, V., Moreno-Roldán, E., Molina-Soberanes, D., Lardelli-Claret, P. Efficacy of training with driving simulators in improving safety in young novice or learner drivers: A systematic review, Transportation Research Part F: Traffic Psychology and Behaviour, Volume 62, 2019, pp. 58-65, ISSN 1369-8478, doi.org/10.1016/j.trf.2018.12.006.

[16] Fleury, D., Brenac, T. Accident prototypical scenarios, a tool for road safety research and diagnostic studies, Accident Analysis and Prevention, 2001, Vol. 33, pp. 267-276, doi: 


\section{$10.1016 / \mathrm{s} 0001-4575(00) 00041-5$}

[17] Michaels, J., Chaumillon, R., Nguyen-Tri, D., Watanabe, D., Hirsch, P., Bellavance, F., et al. Driving simulator scenarios and measures to faithfully evaluate risky driving behavior: A comparative study of different driver age groups. PLoS ONE 12(10): e0185909, 2017. doi.org/10.1371/journal.pone.0185 909

[18] Nitsche, P., Thomas, P., Stuetz, R., Welsh, R. Pre-crash scenarios at road junctions: A clustering method for car crash data, Accident Analysis \& Prevention, Volume 107, 2017, pp. 137-151, ISSN 0001-4575, doi.org/10.1016/j.aap.2017.07.0 11.

[19] Sander, U., Lubbe, N., The potential of clustering methods to define intersection test scenarios: Assessing real-life performance of AEB, Accident Analysis \& Prevention, Volume 113, 2018, pp.1-11, ISSN 0001-4575, doi:10.1016/j.aap.2018.01.010.

[20] Cafiso, S., Di Graziano, A., Pappalardo, G. How to compare different national databases of $\mathrm{HGV}$ accidents to identify issues for safety improvements. The Baltic Journal of Road and Bridge Engineering - Vilnius: Technika, 2013, Vol 8, No 2, p. 124-132 doi:10.3846/bjrbe.2013.16

[21] Mikulík, J., Holló, P., Degener, S., Mdawarima, T.W.M., Kowalski, K., Elsenaar, P.M.W. Road Accident Investigation Guidelines For Road Engineers, World Road Association PIARC Technical Committee - 3.1 "Road Safety", August 2007 Online available from https://www.piarc.org/en/order-1 ibrary/19593-en-Road\%20accident $\% 20$ investigation\%20gui delines $\% 20$ for $\% 20$ road $\% 20$ engineers
[22] Fagerlind, H., Heinig, I., Viström, M., Wisch, M., Sulzberger, L., McCarthy, M., Hulshof, W., Roynard, M., Schaub, S. Analysis of accident data for test scenario definition in the ASSESS project, 4th International Conference ESAR Expert Symposium on Accident Research, Hannover, Germany, 2010 Online available fromhttps://research.chalm ers.se/publication/170719

[23]Hu, W., Xu, X., Zhoua, Z., Liu, Y., Wang, Y., Xiao, L., Qian, $\mathrm{X}$. Mining and comparative analysis of typical pre-crash scenarios from IGLAD, Accident Analysis and Prevention, 145, 2020, 105699, doi: j.aap.2020.105699

[24] Taheri, S.M., Matsushita, K., Sasaki, M. Development of a Driving Simulator with Analyzing Driver's Characteristics Based on a Virtual Reality Head Mounted Display, Journal of Transportation Technologies, Vol.7 No.3, July 2017, doi: $10.4236 /$ jtts.2017.73023

[25] Cafiso, S., Di Graziano, A., Pappalardo, G. In-vehicle Stereo Vision system for identification of traffic conflicts between Bus and Pedestrian, Journal of Traffic and Transportation Engineering, Volume 4, pp. 3-13, 2017 DOI: 10.1016/j.jtte. 2016.05.007, ISSN: 2095-7564

[26] Arena, F., Pau, G., Severino, A. An Overview on the Current Status and Future Perspectives of Smart Cars. Infrastructures 2020, 5, 53. doi: 10.3390/infrastructures5070053

[27] Cafiso, S., D’Agostino, C., Kiec, M., Bak, R. Safety assessment of passing relief lanes using microsimulation-ba sed conflicts analysis. Accident Analysis \& Prevention, Volume 116, pp. 94-102, 2018 DOI: 10.1016/j.aap.2017.07. 001 